\author{
DEPARTAMENTO DE FISIOLOGIA DA FACULDADE DE MEDICINA DA \\ UNIVERSIDADE DE SÃO PAULO \\ Diretor: Prof. Dr. Franklin Augusto de Moura Campos
}

\title{
PESQUISA E IMPORTANCIA DO MANGANÉS EM ALGUNS ALIMENTOS
}

\author{
LIBERATO JOÃO AFFONSO DI DIO \\ ANTONIO CARLOS MAURI
}

Após a publicação do nosso primeiro trabalho sobre o presente assunto (1), aproveitamos o ensejo da realisação do II. ${ }^{\circ}$ Congresso Médico-Estudantino de São Paulo, para apresentarmos uma segunda comunicação a respeito das dosagens do manganês que continuámos a praticar em outros alimentos brasileiros.

Começaremos por enunciar rapidamente os traballhos, todos pertencentes a autores extrangeiros, dedicados ao estudo do manganês, encarando-o sob os mais diversos pontos de vista.

Assim, como pode ser encontrado com maiores detalhes na bibliografia da nossa primeira comunicação, o manganês foi assinalado na beterraba, cenoura, cana de açucar, aveia, chá, café e outras plantas superiores. Foi verificada a sua presença em tecidos animais e vegetais dum modo geral, no leite materno humano, no de vaca e de cabra.

Por uma outra série de trabalhos devidos a autores, em sua grande maioria norte-americanos, concluiu-se que o manganês atua sobre o crescimento, o desenvolvimento normal dos ossos, as trocas celulares em geral certos tipos de fermentação, sobre a hematogênese e a reprodução.

Entretanto, devemos frisar os trabalhos mais importantes que se realisaram sobre o manganês em relação à lactação, trabalhos esses de Orent e Mac Collum (2) e que nos serviram de diretrís para fazermos as nossas pesquisas. Com efeito, demonstraram esses autores que ratas alimentadas com uma dieta șem manganês não amamentavam os seus filhos, repelindo-os toda vês que eles procuravam nutrir-se. Isto é chocante, porquanto é bem conhecido o amor maternal de que são possuidas as ratas; todavia, verifica-se que si assim elas procediam, tornando-se mesmo agressivas, é porque possivelmlente sem manganês as suas glândulas mamárias não elaboram leite necessário para a alimentação de seus filhos. 
Principalmente baseados nestas experiências é que achámos indispensavel inicialmente a posagem do manganês de nossos alimentos, desde que nós pensamos que a presença desse metal tenha uma relação com a lactação humana, como tivemos oportunidade de dizer em nosso primeiro traballho.

O método que empregámos em nossas pesquisas é o do persulfato de amônio de RICHARDS (3), ligeiramente modificado pelo Dr. Aristodemo Melaragno, engenheiro-químico da Repartição de Aguas e xgotos de São Paulo.

Como o método já foi descrito de maneira detalhada em nossa publicação precedente (1), daremos somente uma rápida síntese, frisando as fases principais e o princípio geral em que se baseia:

As dosagens são fietas nas cinzas de alimentos obtidas com uma temperatura de mais ou menos $800^{\circ} \mathrm{C}$, em material sêco ao ar. $\mathrm{O}$ método é colorimétrico, consistindo principalmente na transformação de todas as formas químicas sob as quais o manganês possa encontrar-se em ion permangânico, que conferirá uma côr rósea às soluções, mais ou cenos carregada de acordo com a maior ou menor presença do metal no material analisado. Desde que paralelamente seja preparada uma solução padrão poderemos fazer a comparação colorimétric e calcular a taxa de manganês.

A tabela que daremos a seguir, apresenta todos os resultados novos obtidos.

\begin{tabular}{|c|c|c|c|}
\hline Alimento & $\begin{array}{l}\text { Mn. em } \\
\text { mgms. \% }\end{array}$ & Procedenc & \\
\hline 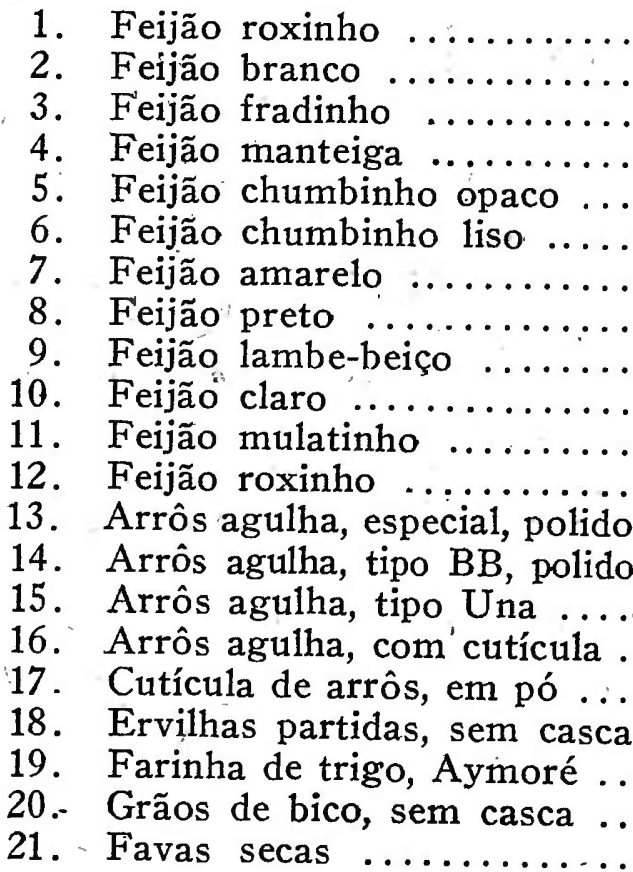 & $\begin{array}{l}1.2 \\
1.9 \\
1.9 \\
1.7 \\
2.5 \\
1.6 \\
1.5 \\
1.4 \\
2.0 \\
2.0 \\
1.6 \\
1.3 \\
0.45 \\
0.57 \\
0.87 \\
2.4 \\
9.9 \\
1.6 \\
0.46 \\
2.3 \\
1.6\end{array}$ & $\begin{array}{l}\text { Minas Gerais. } \\
\text { Paraná. } \\
\text { Zona sorocabana. } \\
\text { Minas Gerais. } \\
\text { Mogí das Cruses. } \\
\text { Sallesopolis. } \\
\text { Minas Gerais. } \\
\text { Zonas araraquarense, }\end{array}$ & sorocabana. \\
\hline
\end{tabular}

Entre os resultados novos, podemos salientar o fató de que a farinha de trigo é muito pobre em manganês; é digno de nota, alem disso, o teor bem elevado apresentado pelos grãos de bico, que como vimos foi de $2.3 \mathrm{mgms}$. \% de manganês, e finalmente a quasi igual- 
dade entre as percentagens obtidas com as favas secas, ervilhas partidas e descascadas e as diversas espécies de feij,o.

Entretanto, como já mostrámos (1), o fato mais interessante foi verificado com o arrôs.

Com efeito, enquanto o arrôs polido apresentou uma taxa de manganês oscilando de 0.45 a $0.87 \mathrm{mgm}$. \% de manganês, no material com a cutícula o teor subiu para $2.4 \mathrm{mgm}$. $\%$.

A dosagem ulterior praticada somente na cutícula do arrôs, reduzida a pó, deu como resultado a elevada taxa de $9.9 \mathrm{mgm}$. \%, mostrando a riquesa notavel de manganês no material que comumente se retira com o polimento a que se submete o arrôs.

Mais uma vês fica assim demonstrado o seguinte fato, já notado por muitos pesquisadores extrangeiros e nacionais, isto é, que a casca de muitos alimentos é a mais importante sob o ponto de vista da nutrição, do que a propria polpa.

Ôs clínicos teem feito notar que são muito comuns em nossos tempos as deficiências de lactação. Paralelamente se sabe, que em tempos idos, não muito remotos, as amas pretas de nossos antepassados, apesar de receberem uma alimentação pobre, constituida em geral de arrôs, feijão, angú, etc. nutriam não só os seus filhos, como os de seus amos... Poderiamos ainda assinalar que não havia um polimento completo desses alimentos e, naturalmente, a cutícula não era acarretada.

Por estes fatos, e ainda por se notar tambem que esses alimentos outrora indispensáveis nas refeições quotidianas, roje estão sendo afastados e quando isso não sucede, um processo de limpeza excessiva acarreta, como já notámos pelos nossos resultados, os elementos nutritivos mais importantes, por estes fatos diziamos, é que nós inferimos a relação entre a falta de manganês e a deficiência de lactação.

Portanto, alem das provas experimentais em ratos, de ORENT e MAC Collum, poderim juntar-se estas outras de indole teórica, mas que em novos estudos poderão ser analisadas.

E' com esse intuito que nós continuaremos a trabalhar, procurando contribuir para a resolução deste problema de importancia transcedental na alimentação dos brasileiros.

\section{BIBLIOGRAFIA}

1 : Dr Dio, L. J. A. \& Maurr, A. C.: "Considerações sobre o teor em Manganês do feijão e do arrôs" - Folia Clinica et Biologica - 19āin, vol. XIII, n. 4, pags. 111-115.

2 - OREnt, E. R. \& MAC Collum, E. V.: "Effect of deprivation of Mn in rat" - J. Biol. Chem., 1931, 92, 651.

3 - RICHARDS, M. B.: "Colorimetric determination of $\mathrm{Mn}$ in biological material" - Analyst, 1930, 55. 


\section{RADIOS 1942 PHILIPS}

Não decida a sua compra sem conhecer'os 8 extraordinarios modelos das Fabricas PHILIPS da U. S. A. e Argentina, desde 1:150\$000 e em prestações.

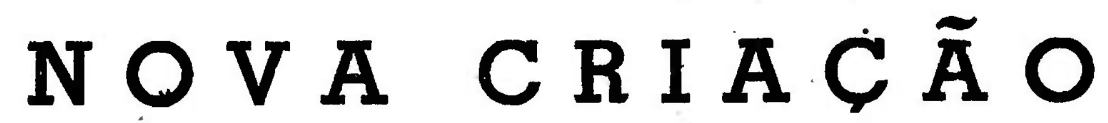

\section{RADIOGRAMOFONE PHILIPS 1942 MODELO 924 AN}

O conjunto de grande potencia mais perfeito no genero, maravilhosamente construido pela Fabrica FHILIPS, de U. S. A., 9. valvulas (4 duplas) com rendimento de 13. Cambiador automatico para 12 discos: FAIXA AMPLIADA de ondas curtas. ALTOFALANTE tipo Concerto de 12 polegadas, etc.

DURANTE O MEZ DE MARÇO OFERTAS ESPECIAIS AOS COMPRADORES DIRETOS

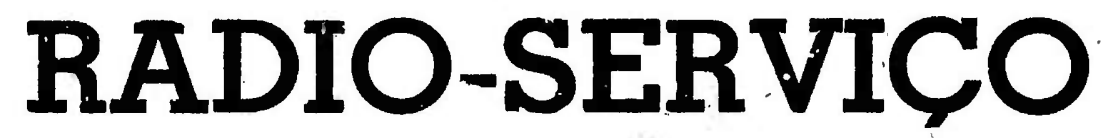

\section{LOJA: RUA BARÃO DE ITAPETININGA, 251 FONE: 4-3056 - CAIXA POSTAL 4.364 - SÃO PAULO}

\section{TRATAMENTO DA ASMA}

\section{$\begin{array}{lllllllllllllllllll} & \text { I } & A & D & R & E & N & A & L & & I & N & H & A & L & A & N & T & E\end{array}$}

Solução concentrada de epinefrina para inhalações.

A inhalaçã̃o de uma substância. capaz de dilatar os brônquios, que ficam contraídos durante o acesso de asma, faz com que desapareçam imediatamente os sintomas.

Este' resultado se obtem facilmente com o Isadrenal Inhalante, que pode ser usado em qualquer aparelho para inhalação, caso não exista o aparelho Isadrenal Inhalador. COMO USAR A SOLUCÃO: - Colocar 20 gotas no aparelho inhalador. Insuflar a pera de borracha, colocando o aparelho verticalmente e dirigido para a boca; ao mesmo tempo inspirar bem fundo, de modo que a vaporização penetre até os pulmões. Poucás insuflações são suficientes para fazer desaparecer o acesso da asma. Terminada a insuflação, o aparelho deve ser fechado com a rolha de borracha e guardado horizontalmente na caixa.

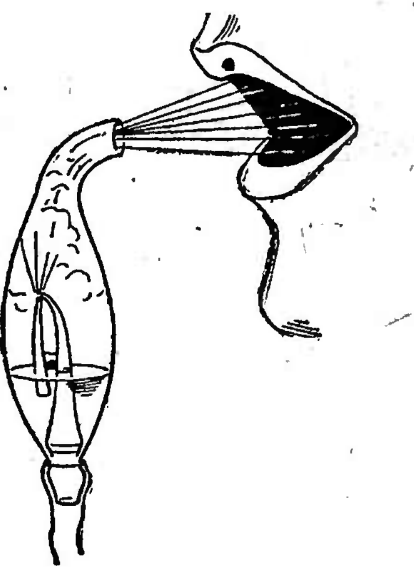

INDÚSTRIA BRASILEIRA DE PRODUTOS QUíMICOS Ltda. MATRIZ: PRAÇA CORNÉliA, 96 - End. Teleg. "ISA" - Tel.: 5-0303 - SÃO PAULO FILIAL: RUA 13 DE MAIO, 44-A - Sala 1001 - RIO DE JANEIRO 